Ansell N (2014) 'Dimensions of global food systems: addressing food security on a world stage' Geopolitics 19(2) 454-460

\title{
Dimensions of global food systems: addressing food security on a world stage
}

In 2007/8 I conducted interviews with government officials and representatives of international donor agencies in Malawi and Lesotho, two countries in which 'food insecurity' has dominated policy discourse. The approaches of the two governments and the stance of the donors differed strikingly. Briefly, Lesotho's Ministry of Agriculture and Food Security was promoting the idea of 'block farming' in which more innovative, commercially-oriented farmers would rent land directly from their neighbours or engage in business partnerships to create larger holdings, and attract outside investment. This plan reflected the government's belief in the efficiency of large scale production and populist attachment to the symbolism of increasing domestic production to reduce reliance on imported food. The donor community, notably DFID, opposed the approach, prioritising the 'food security' side of the 'agriculture and food security' policy. They insisted that investment in grain production in Lesotho could not be economically viable, particularly given the country's membership of a customs union with neighbouring South Africa where food was produced vastly more efficiently. Instead, drawing on Sen's (1981) entitlements approach, they argued that the problem of food insecurity in Lesotho related to the inability of the poor to purchase food, and pushed for a broader focus on enhancing livelihoods.

Malawi's government took a different approach. Rather than alienating its poorest farmers from their land, it provided them with an input subsidy enabling them to purchase hybrid seeds and chemical fertilisers. Donors were initially sceptical (as in Lesotho, they favoured a consumption-focused approach), but domestic production rose considerably, benefiting the poorest (and most food insecure) in particular, and winning the support of least some donors. However, while Malawi has become better able to feed its population with domestically produced food, the scheme depends on imported fertiliser, and as such is arguably environmentally unsustainable.

These two cases highlight how national food policies are, to varying degrees, embedded in global food systems that comprise diverse actors (producers, consumers, markets, industries, government ministries, donor agencies) and institutional structures. They also draw attention to some key issues confronting policy makers seeking to address national food security concerns in a context of these global systems: questions of market efficiency versus domestic self-reliance; increasing production or facilitating consumption; distributional effects between and within countries; use of industrially produced inputs; and the power-laden tensions that exist between institutions and competing ideas. It was with these cases in mind that I read the three books discussed below, each of which analyses global food systems from a different angle. The three authors develop strong explanatory narratives drawing on a wealth of empirical material but differ in their assessments of the processes currently shaping food systems, perspectives on the consequences and prescriptions for ensuring future food security.

In Food Security, Bryan McDonald takes an expansive view of the topic, exploring three dimensions - malnutrition, global environmental change and food safety - through a lens of human security. Charting the 'increasingly globalized network of agricultural and food production systems' (p.148), he draws on diverse disciplinary literatures to illuminate how vulnerabilities in each area are changing and often deepening. As hybrids of nature and society, shaped both by human choices and natural systems, and operating at multiple scales, McDonald argues that global food systems are becoming become ever more integrated, complex and difficult to predict.

The book explores in detail the operation and consequences of various global processes, social, economic, political and technological, that shape risks and vulnerabilities, detailing interactions and complex feedbacks. McDonald illuminates such absurdities of the global system as the shipping of cod from Norway to China for processing, before being returned to Norway. Ultimately, however, the viewpoint is technocratic and managerialist, and fails to consider the significance of power relations or vested interests. Degradation and pollution are, for instance, said to have 'occurred as a result of policy failures and unsustainable agricultural practices' (p.100), but the politics 
Ansell N (2014) 'Dimensions of global food systems: addressing food security on a world stage' Geopolitics 19(2) 454-460

behind such failure is effaced. Similarly, while concerns about Genetically Modified Organisms (GMOs) are itemised (market concentration in the seed industry, intellectual property rights, biological security) the power and operation of the GMO lobby is not mentioned. Agribusiness interests first appear 5 pages from the end of the book, only to be quickly skipped over as discussion returns to the role of international organisations in determining standards, building research capacity and providing emergency relief and other forms of assistance. We are told that 'a growing sense of crisis impelled by trends such as rising food prices, persistent inequalities between rich and poor, and concerns about the expected impacts of global climate change are motivating efforts to adopt new technologies' (p.120) but the author fails to mention the role of commercial interests in promulgating this discourse of crisis and insecurity (see Nally 2011).

By situating his account in a world devoid of political economy, and endeavouring to present an even-handed and dispassionate account, McDonald appears ambivalent towards the global food system in place today. The fact that food production has risen considerably faster than population is celebrated and expected to continue. Improved methods of production including intensification and industrialisation are lauded as partly responsible, while global food chains are commended for giving consumers in developing countries access to cheaper staple crops. At the same time, reservations are expressed, particularly in relation to heightened levels of risk, both of sudden and unexpected events, conveyed rapidly through lengthy supply chains, and pervasive, ongoing threats such as hunger.

In line with his general neglect of power relations, McDonald's prescriptions for enhancing food security also appear politically naïve. The food system, we are told, should be just, equitable and sustainable; this requires the governance of complex transnational challenges and a holistic rather than piecemeal perspective. Changes in policy and regulation nationally and internationally should ensure the global network is managed to deliver in local areas, taking account of complex feedback processes. In some areas, he suggests, a reversal of global integration is required: shorter and less integrated supply chains would reduce the risk of disease transmission, and in some instances, particularly in urban settings, 'strategic decoupling from global networks and the creation of sustainable local food systems' (p.121) is desirable. In keeping with this, the idea of food sovereignty is briefly introduced on final page.

McDonald further asserts that some aspects of malnutrition (such as food choice) are best addressed at individual or domestic level while others (e.g. poverty) are outcomes of national and international trends and stresses. This underplays the extent to which commercial interests shape food choice. Moreover, the author's assertion that it is 'vitally important that individuals and communities be involved in discussions about desired diets' (p.60), and insistence on the need to take into account questions of justice, equity and sustainability, not just economic efficiency, would be more persuasive if the vested interests, power relations and politics that currently inhibit such practices were acknowledged.

One aspect of the global food system that McDonald barely touches on is food aid. This is a significant omission given its role in addressing food insecurity in some parts of the world: it constituted $46 \%$ of Ethiopia's food supply in 2001-3, and in the 1990s accounted for $10 \%$ of the global grain trade. These facts are presented to us by Jennifer Clapp in Hunger in the balance: the new politics of international food aid in which she sets out to explain the shape of global food aid policies and practices. Unusually, Clapp begins by informing the reader that the subject of her book is diminishing in scale and significance, falling by $65 \%$ between 1999 and 2009. Nonetheless, she makes a convincing case for a new study of the subject.

Drawing largely on policy documents and secondary sources, supplemented by some interviews with policymakers, Clapp differs markedly in her approach to McDonald. Her lucid, detailed and carefully argued account is 
Ansell N (2014) 'Dimensions of global food systems: addressing food security on a world stage' Geopolitics 19(2) 454-460

fundamentally concerned with politics. Based on a close reading of the domestic politics of food aid donors and (to a lesser extent) recipients, she argues that decisions relating to food aid relate less to internationally-promoted ideas than to the interests of diverse actors within donor countries - businesses, NGOs, government bureaucracies - combined with domestic institutional dynamics. She considers in some depth the GMO controversy, the role of World Trade Organisation negotiations and outcomes the 2007-8 food crisis, as well as anticipating phenomena likely to shape food aid's future.

Much of Clapp's analysis focuses on the dynamically contrasting positions and policies of the US, EU, Australia, Canada and Japan. In particular, she explores the use of tied food aid, the practice of shipping domestically produced supplies to countries deemed to require it. In the past US food aid was motivated principally by the need to dispose of surplus grain to regulate its own market, while also stimulating potential export markets. Today, tied food aid continues to be functional to various parts of the US economy, notably agribusiness (grain is purchased at above the market rate); shipping (politically influential and paid over \$1bn to transport food aid 2003-6); and even Non-Governmental Organisations (many benefit from the 'monetisation' of food aid, whereby food is sold on the open market in the recipient country to provide NGOs with the finance to cover distribution and other costs). Across the US, $\$ 1 \mathrm{bn}$ in grain sales are said to generate $\$ 2.7 \mathrm{bn}$ in economic activity. There is also a national security argument: food aid supports shipping which might be needed for defence, and the labelling of grain sacks advertises the nation's goodwill.

Strong if familiar arguments against tied food aid are clearly presented: delays (it takes 4-6 months to reach the destination so food commonly arrives at harvest time, after the crisis has passed but with the effect of depressing market prices for local farmers); market distortions (more is provided when stocks are high and prices low); cost inefficiency (65\% of the US food aid budget is spent on transportation); and dietary mismatch (inducing changing tastes and thus import dependency, or rejection of culturally inappropriate foods). At the same time, Clapp makes it very evident that the EU, Australia and Canada have switched from tied aid to Local and Regional Provisioning (LRP), primarily for pragmatic reasons associated with the nature of their agricultural economies, relative strength of domestic lobby groups, or hopes of securing leverage in international negotiations.

While Clapp presents a very carefully reasoned, empirically supported analysis, she does not interpret the processes she elaborates in relation to wider political-economic theory. It would have been interesting to have considered the extent to which the pragmatic decisions of donor governments represent a broader and pervasive neoliberalism. What role did free market ideology play, for instance, in framing the WTO's response to national commercial interests? President Bush supported untying a share of US food aid, but was his stance ideologically driven? Have commercial interests operated through political ideologies as well as through scientific arguments?

Relatedly, while Clapp recognises that donors have their own motives for giving food aid, she does not explicitly consider what the rationale should be. She implicitly suggests that food aid is desirable, but does not justify this, or provide any analysis of the problem that food aid aims to solve. In just one paragraph on the rationale for LRP, she outlines Amartya Sen's contention that famine relates to people's lack of access to food rather than general lack of availability. Yet acceptance of this perspective fundamentally shifts the domain for intervention from supply to demand and production to consumption.

While neither McDonald nor Clapp analyses global food systems in relation to political economic theory, the same cannot be said for Liz Young. Despite being aimed primarily at a student market, Food and Development presents a strong and largely theoretically consistent narrative that explains both hunger and obesity in relation to neoliberal globalisation. The increasing domination of global food systems by profit-hungry corporations (from petrochemical giants and agribusinesses to processing industries and supermarket chains), and the failure to 
Ansell N (2014) 'Dimensions of global food systems: addressing food security on a world stage' Geopolitics 19(2) 454-460

adequately regulate these at national and international levels, is held to account through numerous examples and illustrations drawn from diverse sources. Corporations are shown to expropriate land and resources that would otherwise be used to produce grain for local consumption and instead generate sugar/fat intensive processed foods for global consumption. In contrast to McDonald, Young advocates for 'political interventions that challenge the status quo, rather than limited medical or technical interventions that are fated to be partially effective, if at all' (p.73). This is a very useful introductory text and one that brings together many aspects of global food systems in a highly illuminating if unashamedly partisan way.

Unlike the careful arguments provided in the other two books, Young's broad sweep approach tries to be allencompassing. At times this is at the expense of subtlety, many inconvenient contradictions are simply written out. To some extent this is excusable in a student text; however exploration of such phenomena could have added to rather than detracted from the argument. Food insecurity in North Korea, for instance, is not readily amenable to the same interpretation as food insecurity in a state that is fully integrated into the global capitalist economy. Examination of such differences would sharpen the reader's understanding. Both food sovereignty and Sen's entitlements approach are advocated. Given that the former emphasises local provision of food and maintaining connections between production and consumption, while the latter is unconcerned with the production of food and instead stresses the need for individuals to have means, agricultural or otherwise, of securing consumption, an exploration of the links and contradictions between these perspectives would have been revealing. However, rather than engaging with the problematic individualism of the entitlements approach and its amenability to market-based solutions (hence its favour among Western donors), the book sidesteps this dilemma by ignoring any forms of entitlement beyond access to agricultural land for subsistence production. Young likewise dismisses and refuses to examine impacts of population growth or climate change; some justification is offered for the former, but the latter is not adequately explained. This is problematic insofar as some of empirical material cited assumes these processes to be causal. Moreover, it would have been helpful to have engaged more with the materiality of food and the possibility of real limits to production. Finally, and perhaps less intentionally, some concepts are inadequately problematised. The 'nutrition transition', for instance, is treated as explanatory rather than descriptive, in a way that serves the interests of agribusinesses promising to deliver the types of food expected of 'modern' nation states (see Dixon 2009). The tendency to lack of criticality is exacerbated by overreliance on grey literature for empirical examples and second-hand statistics. Such material is presented in support of particular agendas and is in many cases also factually incorrect.

Factual inaccuracy is unfortunately symptomatic of the poor production qualities that characterise this book. Unlike the other two texts, Food and development needed stronger editorial input. It is very long and marred by repetition and at times a lack of focus. There are countless typographic errors, references missing from the reference list, mislabelled graphs and references to tables that do not exist. Often concepts are inappropriately elided (malnutrition and undernutrition, for instance), and statements at times are simply wrong (for instance the assertion that the under-five mortality rate 'measures the proportion of child deaths that are mainly caused by malnutrition and disease' (p.58)). Sadly, these issues are difficult to ignore when reading the book, and should have been eliminated prior to publication.

The three texts present distinct interpretations of the forces behind global food systems and infer somewhat different consequences for patterns of food consumption and the distribution of hunger and overnutrition, today and in the future. In relation to debates over food policy in Lesotho and Malawi all three books illuminate some of the underlying processes, and the discursive terrain and field of possible action that frame policy production. They point to possible reasons for policy differences, and suggest likely outcomes in relation to addressing hunger. None of the texts, however, gets to grips with the processes that account for the nature of global food systems. For this, the concept of a 'food regime' (see McMichael 2009) offers a valuable means of contextualising current patterns 
and processes. From this perspective, scarcity of food is not a reflection of food regime failure, but 'the logical expression of its central paradoxes, particularly its reliance on over-production in some places and underproduction in others' (Nally 2011: 49). Such insight provides a useful framing for the material presented in each of the texts.

\section{References}

Dixon, J 2009 'From the imperial to the empty calorie: how nutrition relations underpin food regime transitions' Agriculture and Human Values, 26(4)

McMichael, P 2009 'A food regime genealogy' Journal of Peasant Studies 36(1), 139-169

Nally, D 2011 'The biopolitics of food provisioning' Transactions of the Institute of British Geographers 36, 37-53

Sen, A 1981 Poverty and Famines: An Essay on Entitlements and Deprivation, Clarendon Press, Oxford 